\title{
THE EFFICIENCY OF THE INFERENCE SYSTEM KNOWLEDGE STRATEGY FOR THE POSITION CONTROL OF A ROBOT MANIPULATOR WITH TWO DEGREE OF FREEDOM
}

\author{
Fatima Zahra Baghli ${ }^{1}$, Larbi El bakkali ${ }^{2}$, Yassine Lakhal ${ }^{3}$, Abdelfatah Nasri ${ }^{4}$, Brahim Gasbaoui ${ }^{\mathbf{5}}$ \\ ${ }^{2,3}$ Team Modeling and Simulation of Mechanical Systems Laboratory, Abdelmalek Essaadi, Faculty of Sciences, BP.2121, \\ M'hannech, 93002, Tetouan, Morocco,baghli.fatimazahra@gmail.com, larbi_elbakkali_20@hotmail.com \\ 4, 5 Bechar University, B.P 417 Bechar,08000, Algeria,nasriab1978@yahoo.fr, z.gasbaoui@yahoo.com \\ ${ }^{1}$ baghli.fatimazahra@gmail.com
}

\begin{abstract}
The robot manipulator is a mechanical system multi-articulated, in which each articulation is driven individually by an electric actuator is the most robot used in industry, this system need an efficient control strategy.

In this present work we present a new approach for a robot manipulator with two degrees of freedom based on the Fuzzy Logic Controller (FLC) to ensure the position robot control strategy, the proposed control scheme is based on nonlinear dynamic model derived using Lagrange-Euler formulation.
\end{abstract}

Our robot manipulator fuzzy inference system control's simulated in Matlab Simulink environment, the results obtained present the efficiency and the robustness of the proposed control with good performances compared with the classical PID.

Keywords: Robot manipulator, Fuzzy Logic, PID.

\section{INTRODUCTION}

Research on the dynamic modeling and control of the arms manipulators has received increased attention since the last years due to their advantages.

A robot manipulator is a high-speed process that is highly nonlinear, dynamically coupled and often it is not adequate to use linear servo control, if accurate performance in high bandwidth operations is desired. Many efforts have been made in developing control scheme to achieve the precise tracking control of robot manipulators [1]-[2]-[3].

Knowledge based control, expert control and intelligent control are somewhat synonymous and fuzzy control is a particular type of intelligent control. Fuzzy logic control has a great potential since it is able to compensate for the un1certain nonlinear dynamics using the programming capability of human control behavior. The main features of fuzzy control is that a control knowledge base is available within the controller and control actions are generated by applying existing conditions or data to the knowledge base, making us of inference mechanism[4]-[2]. Also, the knowledge base and inference mechanism can handle no crisp, incomplete information; the knowledge itself will improve and evolve through learning and past experience [2].
Fuzzy logic control does not require a conventional model of the process, whereas most conventional techniques require either an analytical model or an experimental model. Fuzzy logic control is particularly suitable for complex and illdefined process in which analytical modeling is difficult due to the fact that the process is not completely known and experimental model identification is not feasible because the required inputs and output of the process may not be measurable [4].

In this work after the system modeling, simulation and control robot manipulator using two articulations for motion using MatLab/Simulink software were carried, when the proposed Fuzzy Logic controlled is used to improve the articulation robot stability. Two types of control PID and FLC were studied and analysed and comparative studies were made.

The reminder paper was structured as follow : the robot modeling is presented in second part of this paper, in the third part of this paper the Fuzzy logic is detailed, the results discussion are presented in the last part of this paper and finally conclusion was given . 


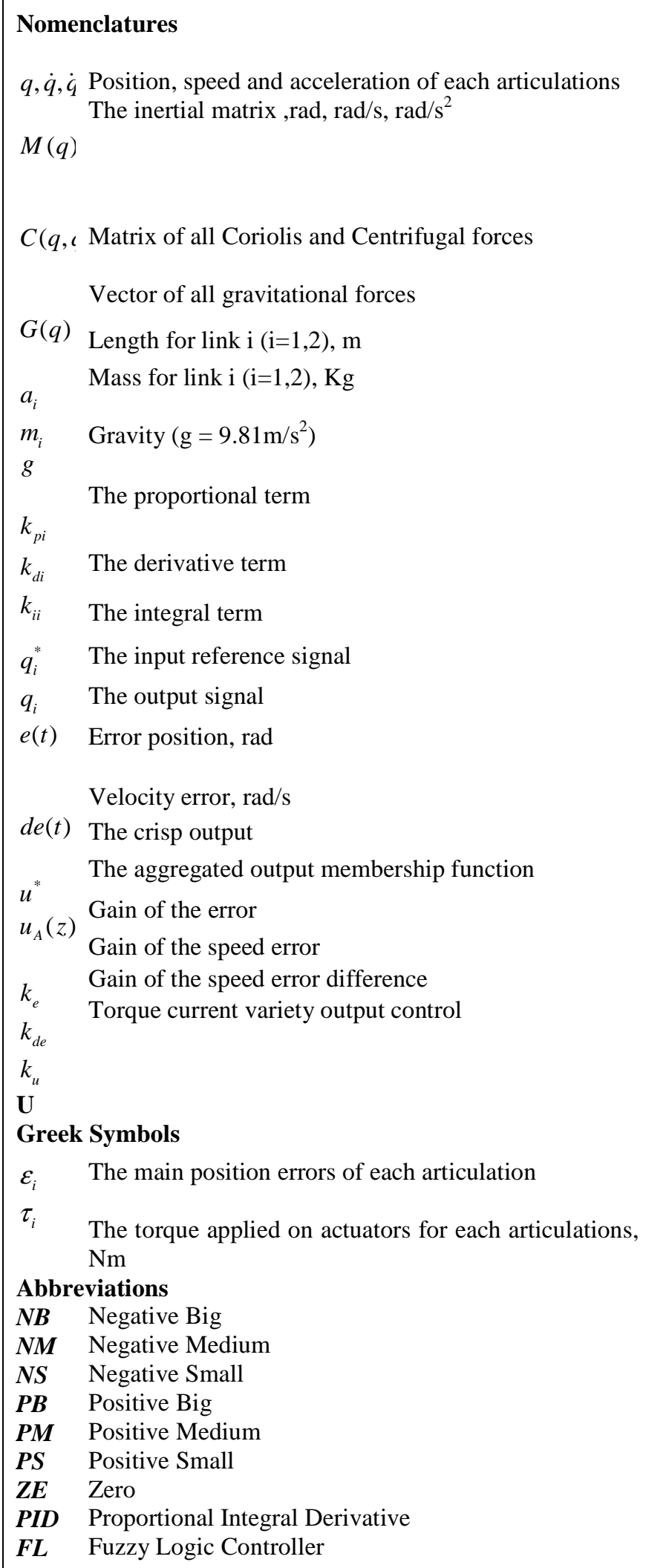

\section{ROBOT DYNAMIC MODELLING}

The dynamical equation of manipulator robot of $\mathrm{n}$ solids articulated between us is given by the following Lagrange method [13]:

$$
\tau=M(q) \ddot{q}+C(q, \dot{q})+G(q)
$$

Where:

$\tau$ is array of $(n \times 1)$ of all efforts applied on actuators, $M(q)$ is the inertial matrix of $(n \times n), C(q, \dot{q})$ present the array of $(n \times 1)$ of all Coriolis and centrifugal forces, $G(q)$ is the array of $(n \times 1)$ of all gravitational references and $q, \dot{q}, \ddot{q}$ are : position, speed and acceleration of each articulations, as it shown on figure.1.

In this figure (Fig1) a schema of a two degree of freedom of arm manipulator is given.

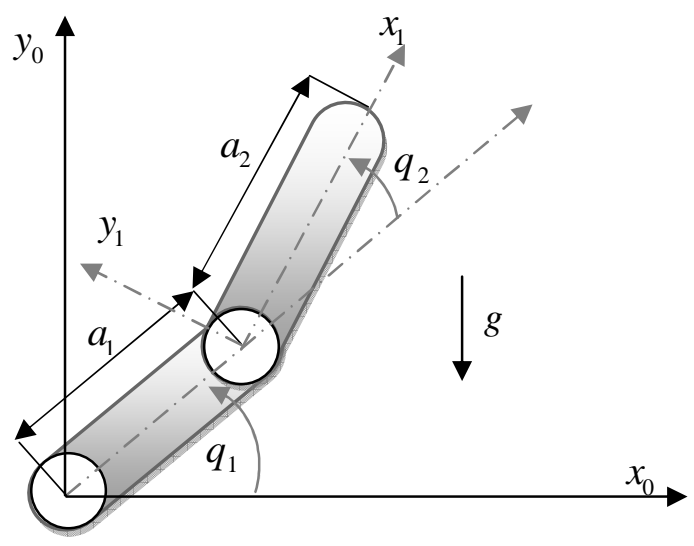

Figure.1. Structure of manipulator robot of two degree of freedom

The robot dynamics is defined as:

$$
\begin{aligned}
& M(q)=\left(\begin{array}{ll}
M_{11} & M_{12} \\
M_{21} & M_{22}
\end{array}\right) \\
& C(q, \dot{q})=\left(\begin{array}{l}
C_{11} \\
C_{21}
\end{array}\right) \\
& G(q)=\left(\begin{array}{l}
G_{11} \\
G_{21}
\end{array}\right)
\end{aligned}
$$




$$
\tau=\left(\begin{array}{l}
\tau_{1} \\
\tau_{2}
\end{array}\right)
$$

With:

$M_{11}=\left(m_{1}+m_{2}\right) a_{1}^{2}+m_{2} a_{2}^{2}+2 m_{2} a_{1} a_{2} c_{2}$

$M_{12}=m_{2} a_{2}^{2}+m_{2} a_{1} a_{2} c_{2}$

$M_{21}=m_{2} a_{2}^{2}+m_{2} a_{1} a_{2} c_{2}$

$M_{22}=m_{2} a_{2}^{2}$

$C_{11}=-m_{2} a_{1} a_{2}\left(2 \dot{q}_{1} \dot{q}_{2}+\dot{q}_{1}^{2}\right) s_{2}$

$C_{21}=m_{2} a_{1} a_{2} \dot{q}_{1}^{2} s_{2}$

$G_{11}=\left(m_{1}+m_{2}\right) g a_{1} c_{1}+m_{2} g a_{2} c_{12}$

$G_{21}=m_{2} g a_{2} c_{12}$

And

$c_{1}=\cos \left(q_{1}\right) \quad c_{2}=\cos \left(q_{2}\right)$

$s_{1}=\sin \left(q_{1}\right) \quad s_{2}=\sin \left(q_{2}\right) \quad c_{12}=\cos \left(q_{1}+q_{2}\right)$

$s_{12}=\sin \left(q_{1}+q_{2}\right)$

The table 1 presents the used robot manipulator simulation parameters

Table-1: The used Robot Parameters

\begin{tabular}{|l|l|}
\hline Phyical system parameter & Value \\
\hline Mass of link 1 (m1) & $0.432 \mathrm{Kg}$ \\
\hline Mass of link 2 (m2) & $0.432 \mathrm{Kg}$ \\
\hline Lenght of link 1 (a1) & $1.5 \mathrm{~m}$ \\
\hline Lenght of link 2 (a2) & $1.2 \mathrm{~m}$ \\
\hline
\end{tabular}

\section{CONTROL LAW USED}

\subsection{Classical PID Controller}

Generally, a classical PID controller of each articulation controlled independently is given with the main following formula $[6,7,8,10]$ :
The classical PID control law of first articulation is given by:

$$
\tau_{1}(t)=K_{p 1} \varepsilon_{1}(t)+K_{d 1} \frac{d \varepsilon_{1}(t)}{d t}+\frac{1}{K_{i 1}} \int \varepsilon_{1}(t) d t
$$

When the classical PID control law of second articulation is given by:

$$
\tau_{2}(t)=K_{p 2} \varepsilon_{2}(t)+K_{d 2} \frac{d \varepsilon_{2}(t)}{d t}+\frac{1}{K_{i 2}} \int \varepsilon_{2}(t) d t
$$

Where: $\varepsilon_{i}=q_{i}^{*}-q_{i}(i=1,2)$ is the main position errors of each articulation controlled independently, $q_{i}^{*}$ is the input reference signal and the terms $K_{p i}, K_{i i}$ and $K_{d i}$ define:

* The proportional term: providing an overall control action proportional to the error signal through the all pass gain factor $[8,9,10]$.

* The integral term: reducing steady state errors through low frequency compensation by an integrator.

* The derivative term: improving transient response through high frequency compensation by a differentiator.

So, the general equation of the manipulator arm by introducing parameters PID controller would be:

$$
\left[\begin{array}{l}
\ddot{q}_{1} \\
\ddot{q_{2}}
\end{array}\right]=M(q)^{-1}[-C(q, \dot{q})-G(q)]+\left[\begin{array}{l}
K_{p 1}\left(q_{1}^{*}-q_{1}\right)+K_{i 1} \int \varepsilon\left(q_{1}\right) d t-K_{d 1} \dot{\varepsilon}_{1} \\
K_{p 2}\left(q_{2}^{*}-q_{2}\right)+K_{i 2} \int \varepsilon\left(q_{2}\right) d t-K_{d 2} \dot{\varepsilon}_{2}
\end{array}\right]
$$

The figure. 2 shows the structure of arm manipulator robot classical PID Control.

\subsection{Fuzzy Logic Position Control Strategy}

The principal design elements in a general fuzzy logic control system shown in Figure. 3 are as follows: Fuzzification, Control rule base establishment and Deffuzification [4]. The figure. 3 shows the Fuzzy logic controller structure 


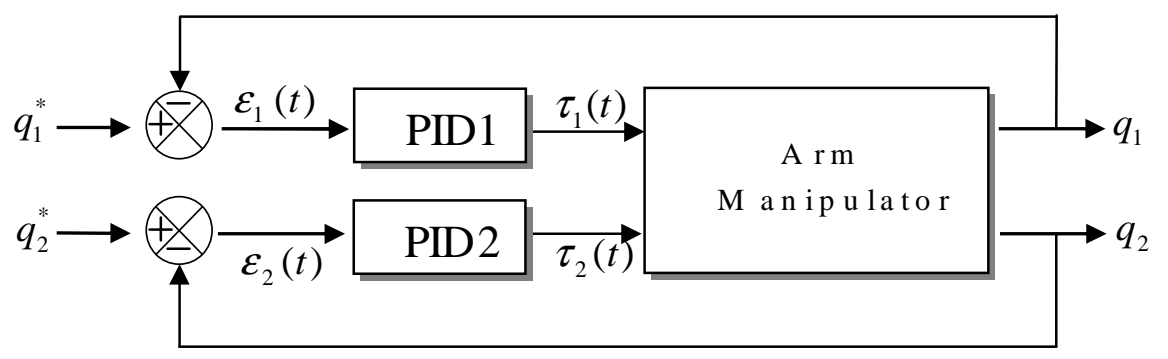

Fig-2: Arm manipulator robot classical PID Control

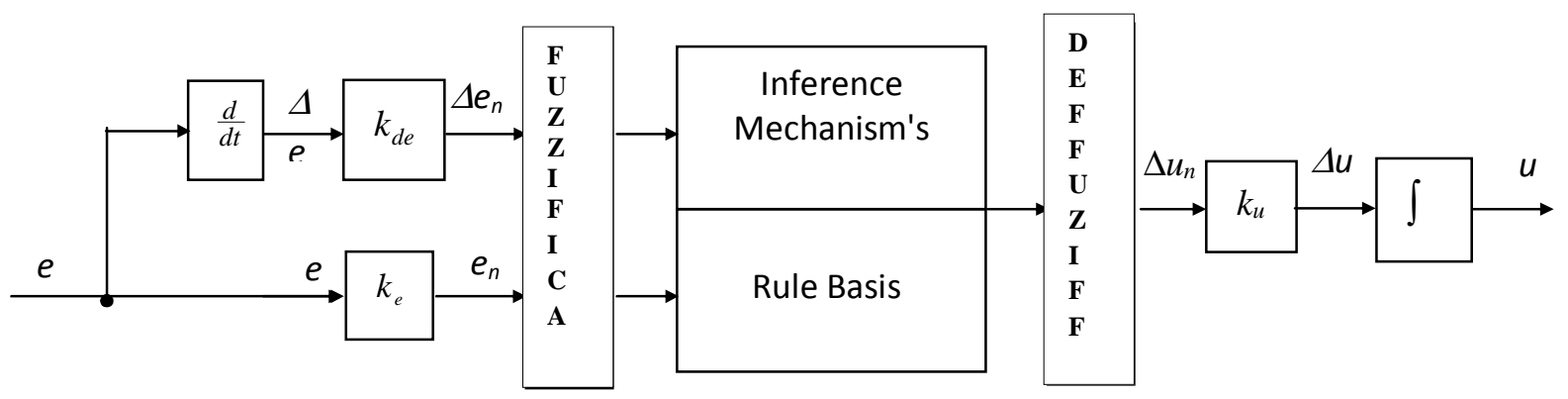

Fig-3: Fuzzy logic controller structure

Where: FUZZIFICA is the Fuzzification process and DEFFUZIFF is the Deffuzification process.

This fuzzy controller is to be designed to automate how a human expert who is successful at this task would control the system. First, the expert tells us (the designers of the fuzzy controller) what information she or he will use as inputs to the decision-making process.

For the robot arm manipulator we will use

$$
e(k)=q_{i}^{*}-q_{i}(i=1,2)
$$

$e(k)=\frac{e(k)-e(k-1)}{\Delta t}$

Where $\Delta t$ is sample cycle, $q_{i}$ is the output signal and $q_{i}^{*}$ is the input reference position, (9) and (10) determine the input variables on which to base decisions. Certainly, there are many other choices [4] (e.g., the integral of the error e could also be used) but this choice makes good intuitive sense.

Clearly, Output variable is also determined by fuzzy logic speed regulator. Because of no particular theory in designing a best rule-base on terms, fuzzy inference based on rule base is artificial from the designer's experiences and experts' knowledge. More terms, and more rules will result in more complicated fuzzy inference.

\subsubsection{Fuzzy Inference System}

The fuzzy inference system has been considered the min-max method (Mamdani), where the implication has been assumed to min and the aggregation has been considered to max. In addition, the Deffuzification method has been considered to the centroid method.

\subsubsection{Input and Output Variables}

The position control of the robot arm manipulator requires two FLC controllers (FLC1 applied to the first joint and FLC2 applied to the second joint). Where two inputs and one output have been considered for the FLC1, same thing for FLC2

The two inputs are $q_{1}^{*}$ (reference position), $\dot{q}_{1}^{*}$ (angular speed) for the first controller and $q_{2}^{*} \dot{q}_{2}^{*}$ for the second controller. The output is $\tau_{1}(t)$ (torque) for FLC1 and $\tau_{2}(t)$ for FLC2. The fiigur. 4 shows the structure of control. 


\subsubsection{Membership Function}

In the proposed fuzzy logic control (FLC1or FLC2), a fiveterm set \{negative big (NB), negative small (NS), zero (ZE), positive small

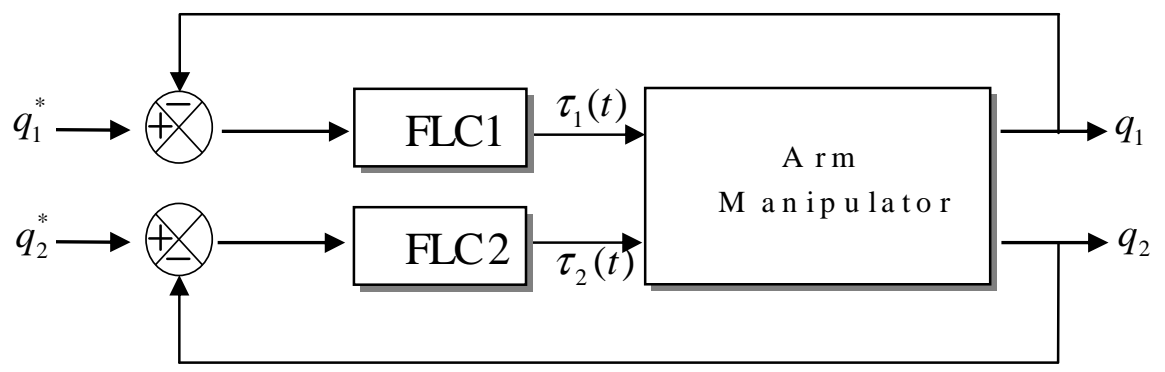

Fig-4: Arm manipulator robot Fuzzy logic control structure

(PS), positive big (PB) is applied to defining input and output linguistic variable.

This present fuzzy logic control is showed in Fig. 5. In this figure, ke, kde, and $\mathrm{ku}$ are gains of the speed error e, speed error difference and torque current variety output control $\mathrm{U}$ here $\mathrm{U}$ means the torque estimed.

A fuzzy set can convert fuzzy input-out term into quantitative description, which is called fuzzification.

Meanwhile, membership function and its discretization are first. to be qualified. The corresponding quantitative input field is defined as $\{-4,-2,0,2,4\}$ and $\{-4,-2,0,2,4\}$ as it shown in figures 5,6 .

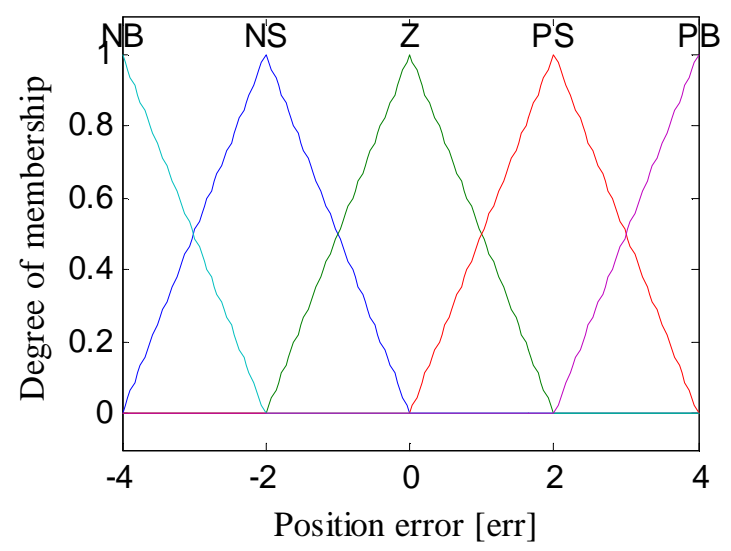

Fig-5: Position error membership functions

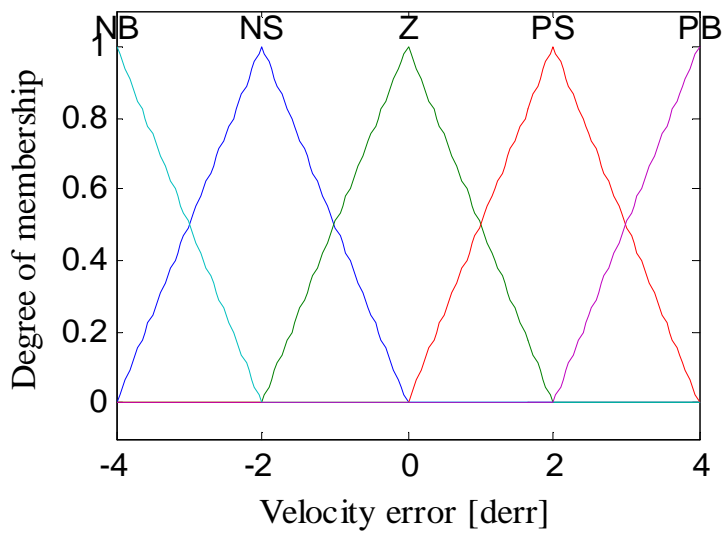

Fig-6: Velocity error membership functions

And the output field is selected as $\{-4,-2,0,2,4\}$. The proposed membership function is figured as Fig. 7.

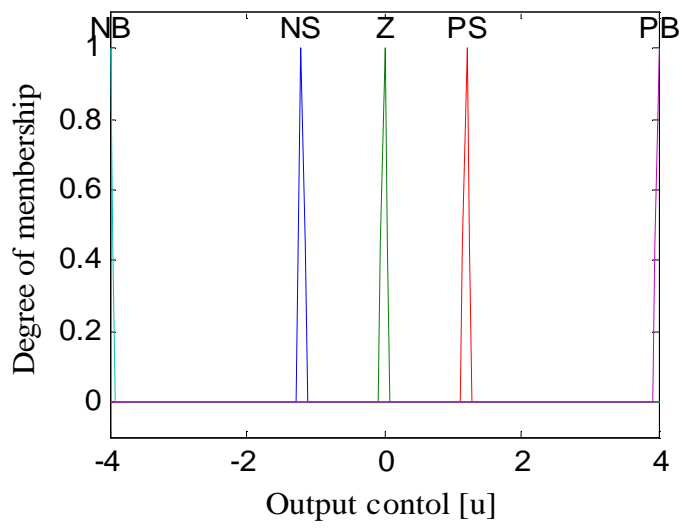

Fig-7: Output control membership functions 


\subsubsection{Fuzzy Rule- Base}

Building fuzzy logic rule is the key step in the improvement of system performance, which is a set of Statements as $\{\mathbf{I F} \ldots$. . THEN . . . . For instance, IF input1 is NB and input2 is NB, THEN output is PB. These rules can be produced by rule base. By off-line calculation and regulation, this fuzzy logic inference rules is showed in the Table 1. However, one can easily design a good fuzzy logic by MATLAB tools.

Table.1. Fuzzy inference rules

\begin{tabular}{|c|c|c|c|c|c|c|}
\hline \multirow{2}{*}{\multicolumn{2}{|c|}{$u(t)$}} & \multicolumn{5}{|c|}{$e(t)$} \\
\hline & & NB & NS & $\mathbf{Z}$ & PS & PB \\
\hline \multirow{5}{*}{$d e(t)$} & NB & NB & NB & $\mathrm{NS}$ & $\mathrm{NS}$ & $\mathrm{Z}$ \\
\hline & NS & NB & $\mathrm{NS}$ & $\mathrm{NS}$ & $\bar{Z}$ & PS \\
\hline & $\mathbf{Z}$ & $\overline{\mathrm{NS}}$ & $\mathrm{NS}$ & $\mathrm{Z}$ & PS & PS \\
\hline & PS & $\mathrm{NS}$ & $\mathrm{Z}$ & PS & PS & $\mathrm{PB}$ \\
\hline & PB & Z & PS & PS & PB & $\mathrm{PB}$ \\
\hline
\end{tabular}

Where: e (t) and de (t) are the position error and the velocity error variation respectively.

Surface plot depicted in Figure. 8 shows the relationship between error [err] and Derivative of Error [deer] on the input side, and controller output $[\mathrm{u}]$ on the output side. The plot results from a rule base with Twenty five rules and the surface is more or less bumpy. The horizontal plateaus are due to flat peaks in the input sets. The plateau around the origin implies a low sensitivity towards changes in either Error or Derivative of error near the reference. This is an advantage if the noise sensitivity must be low when the process is near the reference.

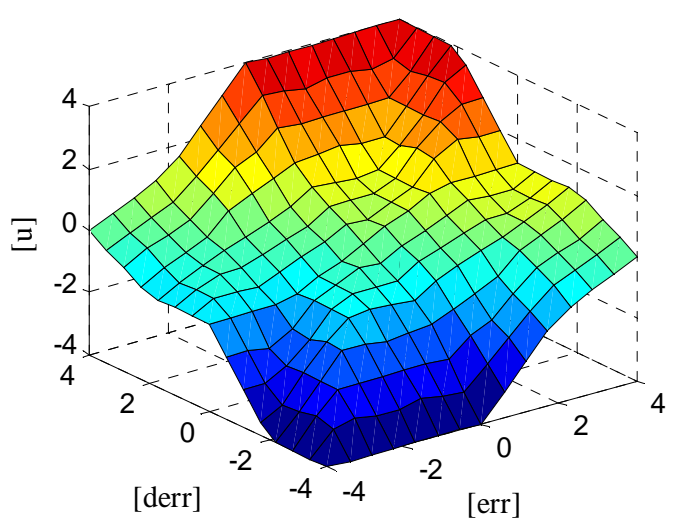

Fig-8: Control surface

\subsubsection{Deffuzification}

The Deffuzification is required to transform fuzzy control signal into exact control output. The weighted centroid method is applied to deffuzzify the fuzzy control signal. This method can be expressed as:

$$
u^{*}=\frac{\int_{z} u_{A}(z) \cdot z d z}{\int_{z} u_{A}(z) d z}
$$

Where, $u_{A}(z)$ is the aggregated output membership function and $u^{*}$ is the crisp output.

\section{SIMULATION}

SISO control based on classical PID model and intelligent control based on FLC model were tested to sinus response trajectory. This simulation applied to two degrees of freedom robot arm was implemented in Matlab/Simulink. Trajectory performance and position error are compared in these controllers.

\section{- The trajectory performances:}

Figures $(9,10,11$, and 12) are show tracking performance for first and second arm (link) with PID and FLC for sinus trajectories.

By comparing sinus trajectory with PID and FLC:

For the first link (joint) controlled by PID, the output does not coincide with the reference (Fig.9) but by the FLC they coincident as shown in (Fig.10), the overshoot PID's higher than FLC1

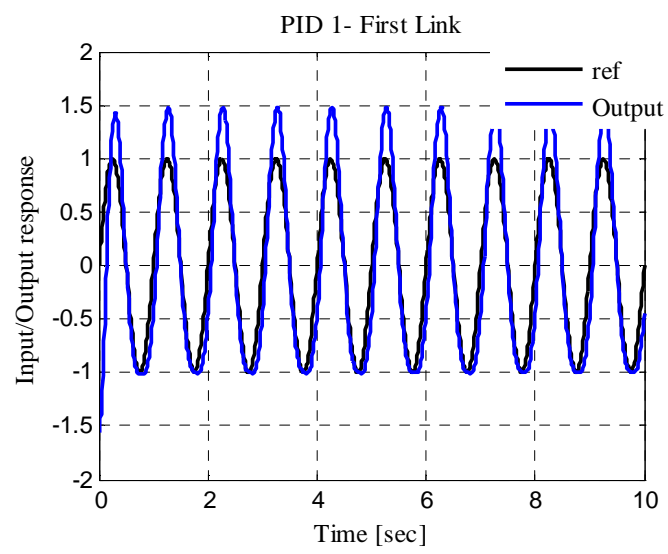

Fig-9: PID (First link trajectory) 


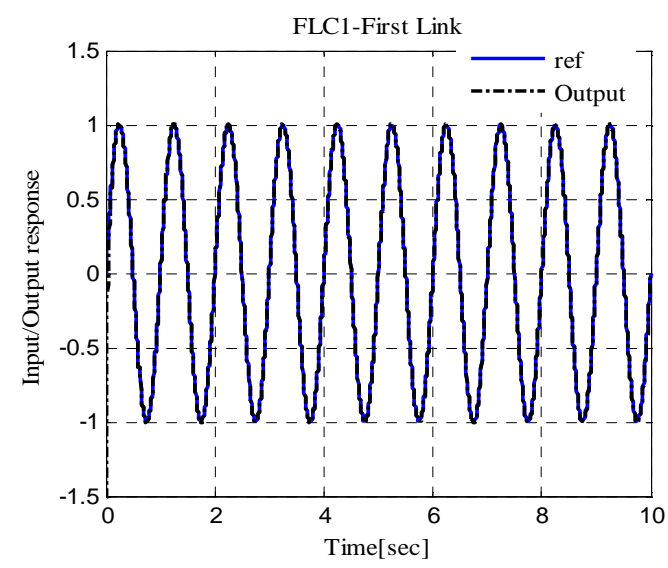

Fig-10: FLC (First link trajectory)

For the second link controlled by PID, the output does not attaint the reference signal (Fig.11) but by the FLC they coincident as shown in (Fig.12).

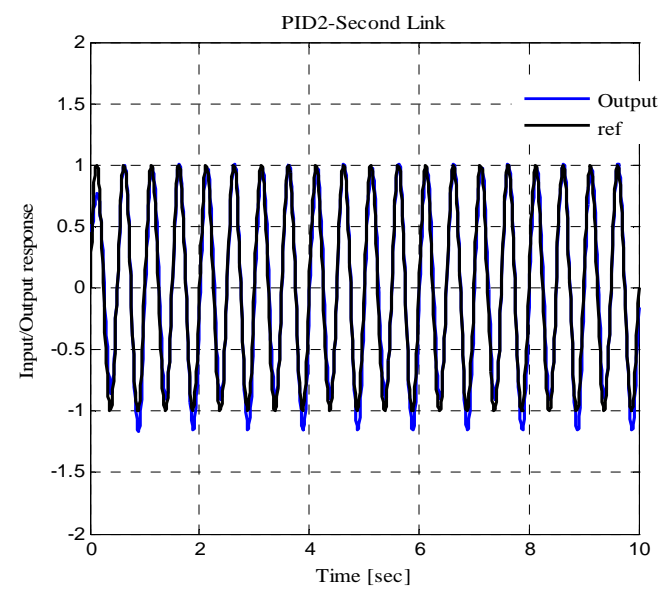

Fig-11: PID -Second link trajectory

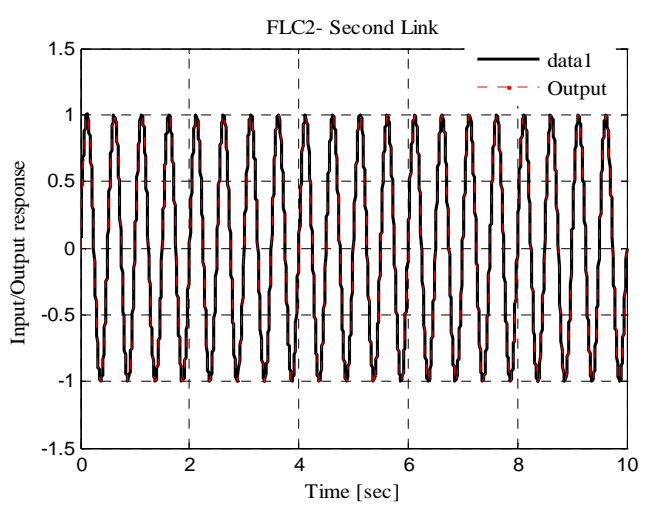

Fig-12: FLC (Second link trajectory)

\section{-data1: ref}

Error computation compare :

Figures $(13,14,15$, and 16) are shown error performance, by comparing position error for the first and second link. The FLC Control ensure the robot manipulator's stability by maintaining the error position equal to zero $\left(\varepsilon_{1}=\varepsilon_{1}=0\right.$ ) so PID (i)'s error position is respectively higher than FLC (i) where $(i=1,2)$.

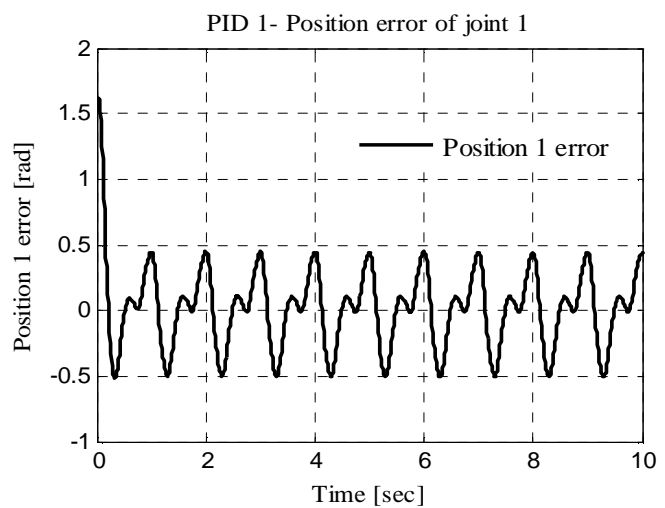

Fig-13: PID 1 for the first link position error

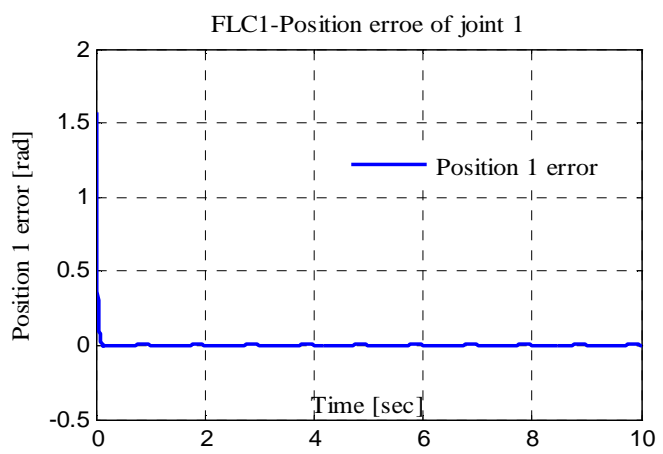

Figure.14. FLC 1 for the first link position error

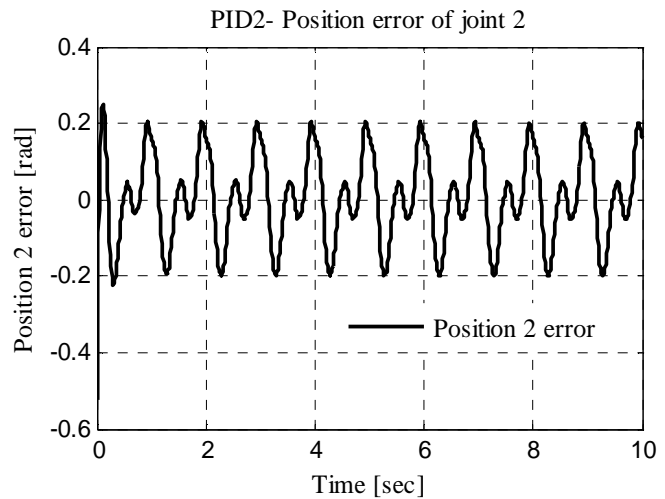

Figure.15. PID 2 for the second link position error 


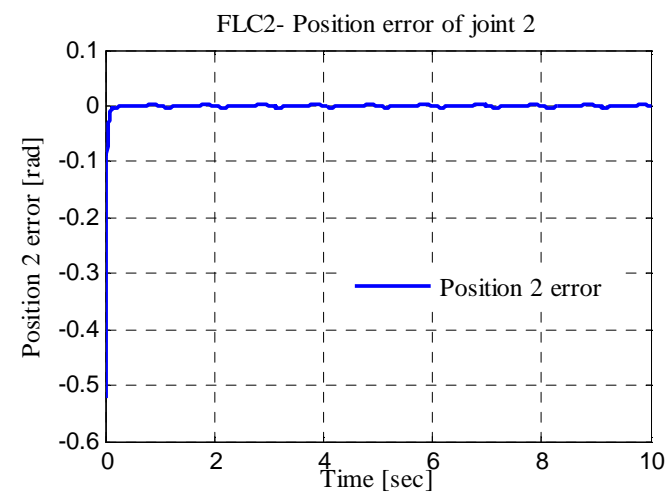

Fig-16: FLC 2 for the first link position error

We can summaries all the obtained results in the table 2:

Table-3: PID and FLC Results

\begin{tabular}{|l||l|l|l||l||}
\hline Controller & PID1 & PID2 & FLC 1 & FLC2 \\
\hline \hline Links & Link1 & Link2 & Link1 & Link2 \\
\hline $\begin{array}{l}\text { Position } \\
\text { error[rad] }\end{array}$ & 0.445 & 0.159 & 0.003 & 0.001 \\
\hline \hline overshoot [\%] & $5 \%$ & - & $0 \%$ & $0 \%$ \\
\hline \hline Torque [Nm] & 185.9 & 1034 & 117.1 & 288.2 \\
\hline \hline Rise time [s] & 0 & 0 & 0 & 0 \\
\hline
\end{tabular}

\section{CONCLUSIONS}

In this present work an arm manipulator robot using two degree of freedom was controlled using two types of controls strategies, SISO control based on classical PID model and intelligent control based on Fuzzy logic (FLC), this last one present maximum control structure of our control model and give more and more efficiency for the robot model with more position stability and good dynamical performances with no overshoot so industrials would take into account the efficiency of the developing control model for the futures two freedom robot design considerations

\section{REFERENCES}

[1]. H.Asada \& J.J.Slotine, "Robot analysis and Control", New york:Wiley, 1986.

[2]. P.Sumathi,"Precise tracking control of robot manipulator using fuzzy logic", DARH2005 conference, session4.1

[3]. F.L. Lewis,C.T. Abdallah, and D.M. Dawson, "Control of Robot manipulators", New York: Macmillan, 1993.

[4]. M.Kevin, Passino and Stephan yurkovich," Fuzzy logic", Addison Wesley longman 1998
[5]. Atef A.ata, "Optimal trajectory planning of manipulator: review", Journal of Engineering Science and Technology, 2(1) 2007,32-54.

[6]. Ang K.H., Chang G., Yun Li, PID control system analysis, design and Technology, IEEE Transaction on Control System Technology, 2005, 13(4), p. 559-577.

[7]. Astrom K.J., Hagglund T., PID controllers: theory, design, and tuning, 2nd ed.Instrument society of America, 1995.

[8]. Wang J.S., Zhang Y., Wang W., Optimal design of PI/PD controller for non- Minimum phase system,Transactions of the Institute of Measurement and Control, 2006, 28(1),27-35.

[9]. Bingul Z., "A new PID tuning technique using differential evolution for unstable and integrating processes with time delay", ICONIP, Proceedings Lecture Notes in Computer Science, 2004, 3316, p. 254-260.

[10]. Boumediène Allaoua, Abdellah Laoufi and Brahim Gasbaoui ," Multi-Drive Paper System Control Based on Multi-Input Multi-Output PID Controller" Leonardo Journal of Sciences, Issue 16, January-June 2010, p. 59-70.

[11]. Muna H. Saleh, Arif Al-Qassar, Mazin Z. Othman, Abdulkarem Sh. Mahdi," Devloppement of the CrossCoupling phenomena of MimoFlight system using fuzzy logic controller",

[12]. David I, Robles G, PID control dynamics of a Robotic arm manipulator with two degrees of Freedom, Control of Processos Robotica, August 17, 2012.

[13]. F.Baghli, Y.Lakhal, L.El bakkali, Contrôle dynamique d'un bras manipulateur à deux dégrées de liberté par un contrôleur PID, 11ème Congrès International de Mécanique, Agadir 23 ,26 avril 2013.

[14]. C.Ham, Z.Qu and R.Johnson,"Robust fuzzy control for robot manipulators". IEE proceedings on Control Theory Applications, Vol.147.No.2, March 2000

[15]. J.J spong and M.Vidyasagar, "Robot dynamics and Control", New york: Wiley, 1989 